\title{
ANALISIS EFEKTIVITAS SISTEM PENGENDALIAN MANAJEMEN PENGGAJIAN PADA PT. AURA MANDIRI
}

\author{
Oleh: \\ Febie Aleyda Yahya \\ Sherly Agustin E.B \\ Irfan Setyanto \\ Muhammad Ardi Nupi Hasyim \\ Institut Manajemen Koperasi Indonesia \\ email: febiealeydayahya@gmail.com
}

\begin{abstract}
The Current era requires speed and accuracy in making decisions, so that potential factors of production are needed. The existence of human resources as the main factor, then provides a reward for the achievements achieved in the form of salary. Provision of ineffective salaries can cause problems for the company, especially in relation to HR performance. To avoid this, it is necessary to control payroll management that ensures the fulfillment of the rights of workers (employees).The reward given by the company for the achievements of the workforce (employees) is salary. Ineffective payrolls cause problems for companies related to the performance of human resources (HR). To avoid this problem, a payroll management control system is needed to protect the rights of workers (employees). This study aims to analyze the effectiveness of the payroll management control system at PT. Aura Mandiri. The research method used is descriptive qualitative method. The results showed that the payroll management control system at PT. Aura Mandiri is quite effective because the company carries out procedures from start to finish and there are some other functions that are inadequate, namely the employee attendance list is still manual and has not taken advantage of more sophisticated technology, for example using a fingerprint system.
\end{abstract}

Keywords: Effectiveness, Management Control System, Payroll

\section{PENDAHULUAN}

Menurut Suadi, sistem pengendalian manajemen merupakan semua sistem yang terdiri dari beberapa sub sistem yang saling berkaitan, seperti pemrograman, penganggaran, akuntansi, pelaporan, dan pertanggungjawaban untuk membantu manajemen mempengaruhi orang lain dalam sebuah perusahaan, agar mau mencapai tujuan perusahaan melalui strategi tertentu secara efektif dan efisien.
Sistem pengendalian manajemen dapat dikatakan memadai apabila sistem tersebut diterapkan pada perusahaan mencapai tujuan perusahaan. Sistem pengendalian manajemen memiliki peran penting dalam perusahaan, seperti halnya sistem penggajian. Sistem penggajian yang baik diselingi dengan sistem pengendalian manajemen yang baik. 
Penelitian yang terkait dengan sistem penggajian telah dilakukan sebelumnya, diantaranya seperti penelitian Aminatul Husniyah, Darminto, dan Dwiatmanto dengan judul "Analisis Pengendalian Internal Pada Sistem Penggajian Karyawan" studi pada RSUD Dr. H. Moh. Anwar Sumenep, menyimpulkan bahwa pengendalian internal pada sistem penggajian karyawan yang diterapkan oleh manajemen belum dilakukan dengan baik, karena salah satu unsur pengendalian internalnya terdapat kelemahan yaitu pada struktur organisasi, dimana fungsi keuangan RSUD Dr. H. Moh. Anwar Sumenep.

Berdasarkan penelitian diatas, peneliti tertarik untuk melakukan penelitian sistem penggajian dengan judul "Analisis Efektivitas Sistem Pengendalian Manajemen Penggajian" studi pada PT. Aura Mandiri. PT. Aura Mandiri merupakan perusahaan yang bergerak dibidang pertambangan batu, dan pasir yang berlokasi di Pasaman, Sumatera Barat.

Penelitian ini mengangkat rumusan masalah yakni apakah efektivitas sistem pengendalian manajemen penggajian pada PT. Aura Mandiri sudah efektif?

Dengan tujuan penelitian ini untuk menganalisis efektivitas sistem pengendalian manajemen penggajian pada PT. Aura Mandiri.

\section{KERANGKA TEORITIS DAN HIPOTESIS}

\section{Tinjauan Pustaka}

Robert J. Mockler menyatakan bahwa sistem pengendalian manajemen adalah segala upaya sistematis oleh manajemen bisnis untuk membandingkan kinerja dengan standar yang telah ditentukan, rencana, atau tujuan untuk menentukan apakah kinerja sejalan dengan standar tersebut dan mungkin untuk mengambil tindakan perbaikan yang diperlukan untuk melihat bahwa manusia dan sumber daya perusahaan lainnya yang digunakan dengan cara yang paling efektif dan efisien mungkin dalam mencapai tujuan perusahaan.

Suatu sistem pengendalian memiliki beberapa elemen yang memungkinkan pengendalian berjalan baik. Elemen-elemen tersebut adalah (Halim dkk, 2009:5):

1. Sensor atau detektor, yaitu suatu alat untuk mengindentifikasi apa ang sedang terjadi dalam suatu proses.

2. Assesor, yaitu suatu alat untuk menentukan ketepatan. Biasanya ukurannya dengan membandingkan kenyataan dan standar yang telah ditetapkan.

3. Efektor, yaitu alat yang digunakan untuk mengubah sesuatu yang diperoleh dari assesor.

4. Jaringan komunikasi, yaitu alat yang mengirim informasi antara sensor atau 
detektor dan assesor dan antara assesor dengan efektor.

Hariandja (2002) menyatakan bahwa gaji adalah salah satu unsur yang sangat penting yang bisa mempengaruhi kinerja pegawai, sebab gaji dapat dikatakan sebagai alat untuk memenuhi berbagai kebutuhan pegawai itu sendiri, sehingga dengan gaji yang diberikan pegawai akan lebih termotivasi untuk bekerja lebih giat, tekun, dan memaksimalkan kemampuan yang dimilikinya secara maksimal.

Tujuan penggajian antara lain:

\section{Motivasi}

Adanya balas jasa (pembayaran gaji) yang diberikan kepada manajer cukup besar, manajer akan memotivasi karyawannya.

2. Kepuasan Kerja

Adanya balas jasa (pembayaran gaji) yang diberikan kepada karyawan, karyawan akan memenuhi kebutuhan - kebutuhan fisik, status sosial, dan egoistik sehingga memperoleh kepuasan kerja dari jabatannya.

3. Disiplin

Adanya balas jasa (pembayaran gaji) yang diberikan kepada karyawan, maka disiplin karyawan semakin baik. Karyawan akan menyadari serta menaati peraturan - peraturan yang berlaku.
4. Stabilitas Karyawan

Adanya program kompensasi atau prinsip adil dan layak serta eksternal konsistensi yang kompentatif, maka stabilitas karyawan lebih terjamin.

5. Ikatan Kerjasama

Adanya pemberian gaji terjalinlah ikatan kerjasama formal antar atasan dengan karyawan. Karyawan harus mengerjakan tugas - tugas dengan baik, sedangkan atasan wajib membaar gaji yang sesuai dengan perjanjian yang telah disepakati.

Ravianto (2014:11) menyatakan bahwa efektivitas adalah seberapa baik pekerjaan ang dilakukan, sejauh mana orang menghasilkan keluaran sesuai dengan yang diharapkan. Artinya apabila suatu pekerjaan dapat diselesaikan sesuai dengan perencanaan, baik dalam waktu, biaya, maupun mutunya maka dapat dikatakan efektif.

Tolak ukur atau kriteria efektivitas antara lain:

1. Pemisahan Fungsi

Artinya adalah perlu disusunnya fungsi - fungsi dalam suatu organisasi beserta dengan tugas, wewenang, dan tanggungjawab masing - masing.

2. Analisis Pekerjaan

Artinya adalah perlu disusunnya deskripsi jabatan, uraian pekerjaan, 
standar pekerjaan yang terdapat dalam suatu organisasi.

3. Penilaian yang dikaitkan dengan keadaan Internal

Artinya adalah dalam menentukan penilaian, diusahakan urutan peringkat pekerjaan tersusun dengan baik.

Beberapa penelitian terdahulu yang terkait dengan sistem penggajian

Tabel 1. Penelitian Terdahulu

\begin{tabular}{lll}
\hline No. & Nama Peneliti / Tahun & Judul \\
\hline 1. & $\begin{array}{l}\text { Aminatul Husniyah, Darminto, dan Dwiatmanto } \\
(2015)\end{array}$ & $\begin{array}{l}\text { Analisis Pengendalian Internal Pada } \\
\text { Sistem Penggajian Karyawan } \\
\end{array}$ \\
& & $\begin{array}{l}\text { (Studi Pada RSUD Dr. H. Moh. } \\
\text { Anwar Sumenep) }\end{array}$ \\
\hline 2. & Ribka Fininalce Tampi, dan Jantje J. Tinangon & $\begin{array}{l}\text { Analisis Sistem Pengendalian Intern } \\
\text { Terhadap Penggajian Pada Grand }\end{array}$ \\
& $(2015)$ & Sentral Supermarket Tomohon. \\
\hline 3. & Sifra Green Sinain & Analisis Efektivitas Pengendalian \\
& $(2013)$ & Manajemen Penggajian \\
& & PT. PLN (Persero) Rayon Tomohon. \\
\hline
\end{tabular}

\section{METODE PENELITIAN}

Penelitian ini menggunakan penelitian deskriptif dengan metode analisis data yaitu analisis data kualitatif. Mardalis (2010:26) menyatakan bahwa penelitian deskriptif, bertujuan untuk mendeskripkan apa - apa yang saat ini berlaku. Didalamnya terdapat upaya mendeskripsikan, mencatat, analisis dan mengintreprestasikan kondisi - kondisi yang sekarang ini terjadi atau ada. Penelitian ini berfokus pada sistem penggajian dan sistem pengendalian manajemen pada PT. Aura Mandiri dan tidak menguji hipotesa atau tidak menggunakan hipotesa, melainkan hanya mendeskripsikan informasi apa adanya sesuai dengan variabel - variabel yang diteliti.
Pengumpulan data yang digunakan yaitu kepustakaan dengan menggunakan bahan-bahan yang diperoleh dari literaturliteratur yang berhubungan dengan pengendalian manajemen penggajian serta wawancara dengan mengadakan tanya jawab langsung kepada pihak yang terkait dalam perusahaan. Metode ini digunakan untuk memperoleh data tentang gambaran umum perusahaan, prosedur penggajian karyawan, serta unit-unit organisasi yang terkait dengan penggajian. 


\section{HASIL PENELITIAN DAN PEMBAHASAN}

\section{Analisis Sistem Pengendalian}

Manajemen Penggajian Pada PT. Aura

Mandiri

Dokumen-dokumen yang digunakan:

- Daftar hadir karyawan, untuk mencatat kehadiran karyawan setiap hari pada saat datang sebelum memulai kerja dan pulang kerja degan melakukan absensi manual yang diawasi oleh bagian pencatatan kehadiran.

- Daftar gaji karyawan untuk mencatat jumlah gaji pokok dari masing masing karyawan, ditambah tunjangan - tunjangan dan dikurangi potonganpotongan.
Slip gaji, slip gaji dibuat oleh bagian akuntansi yang berisi rincian gaji yang diterima oleh karyawan.

Dokumen - dokumen untuk penggajian pada PT. Aura Mandiri sudah cukup baik dan sesuai dengan teori yang ada. Dokumen yang digunakan sudah cukup memadai dalam mendukung sistem pengendalian manajemen penggajian. Tetapi masih ada sebagian fungsi yang belum dimanfaatkan seperti sistem fingerprint, gaji karyawan tanpa transfer rekening, serta rekap harian yang masih manual.

\section{Analisis Efektivitas Unsur-Unsur Sistem Pengendalian Manajemen Pada PT Aura Mandiri}

Tabel 2. Analisis Efektivitas Unsur-Unsur Sistem Pengendalian Manajemen Pada PT Aura Mandiri

\begin{tabular}{|c|c|}
\hline $\begin{array}{l}\text { Unsur-Unsur Sistem Pengendalian } \\
\text { Manajemen }\end{array}$ & Hal-Hal Yang Mendukung \\
\hline $\begin{array}{l}\text { Keahlian karyawan (pegawai) sesuai dengan } \\
\text { tanggung jawabnya. }\end{array}$ & $\begin{array}{l}\text { Hal ini dapat terlihat dengan adanya pelatihan } \\
\text { terlebih dahulu sebelum pegawai diterima } \\
\text { bekerja. }\end{array}$ \\
\hline Pemisahan tugas. & $\begin{array}{l}\text { Sudah terdapat pemisahan tugas yang cukup jelas } \\
\text { dan dapat dilihat dari struktur organisasi yang } \\
\text { ada }\end{array}$ \\
\hline $\begin{array}{l}\text { Sistem pemberian wewenang, tujuan dan teknik } \\
\text { serta pengawasan yang wajar untuk mengadakan } \\
\text { pengendalian atas harta, utang, penerimaan, dan } \\
\text { pengeluaran. }\end{array}$ & $\begin{array}{l}\text { Hal ini dapat dilihat dari penjabaran tugas } \\
\text { manajer area point ke tiga yaitu mengatur dan } \\
\text { mengarahkan kegiatan pengendalian dan } \\
\text { pengawasan, pelaksanaan, dan pemeliharaan } \\
\text { jaringan. }\end{array}$ \\
\hline & \\
\hline
\end{tabular}




\begin{tabular}{ll}
\hline & $\begin{array}{l}\text { kebenarannya. Selain itu, dokumen-dokumen } \\
\text { disimpan dengan baik dan rapi sehingga } \\
\text { memudahkan untuk mencari pada saat } \\
\text { diperlukan. }\end{array}$ \\
\hline $\begin{array}{l}\text { Periksa fisik harta dengan catatan - catatan } \\
\text { harta dan utang, dan mengadakan tindakan } \\
\text { koreksi jika dijumpai adanya perbedaan. }\end{array}$ & $\begin{array}{l}\text { Segala catatan-catatan yang ada selalu diperiksa } \\
\text { setiap harinya, dan langsung dikoreksi saat itu } \\
\text { juga jika terjadi kesalahan pada catatan tersebut. }\end{array}$ \\
\hline
\end{tabular}

\section{Analisis Prosedur Dalam Sistem Penggajian pada PT Aura Mandiri}

Fungsi-fungsi yang terkait dalam sistem pengendalian manajemen penggajian pada PT Aura Mandiri adalah:

a. Direktur

Direktur berwenang dalam proses pembayaran gaji pokok karyawan. Melakukan transfer gaji pokok, tunjangan transport, uang makan, dan premi hadir ke masing - masing karyawan dan menbayar biaya pembayaran pendapatan per bulan ke Bagian Akuntansi.

b. Bagian Akuntansi

Bagian akuntansi bertugas untuk membuat rekap daftar hadir karyawan, daftar gaji karyawan, slip gaji, lembar penerimaan gaji, bukti kas keluar, dan bertanggung jawab mencatat transaksi - transaksi penggajian pada jurnal umum dan buku besar.

Fungsi-fungsi yang terkait dengan sistem informasi akuntansi penggajian pada sistem pengendalian manajemen penggajian pada PT. Aura Mandiri kurang baik.
Alternatif - alternatif untuk mengurangi kelemahan pada fungsi - fungsi yang terkait dalam sistem informasi akuntansi penggajian yaitu antara lain :

- $\quad$ Terdapat bagian khusus seperti fungsi pembuat daftar gaji (bagian akuntansi) yang bertanggung jawab untuk membuat daftar gaji yang berisi gaji pokok serta tunjangan-tunjangan yang diberikan kepada karyawan dan potongan - potongan yang menjadi beban karyawan setiap bulannya.

- Daftar gaji tersebut dikelola oleh fungsi pembuat daftar gaji guna pembuatan daftar gaji yang akan diajukan ke kasir, untuk pembayaran gaji pegawai.

- Fungsi pencatat waktu (bagian personalia) yang bertanggungjawab untuk membuat rekap daftar hadir karyawan dan menyelenggarakan waktu hadir bagi semua karyawan PT. Aura Mandiri. Sistem pengendalian intern yang baik mensyaratkan fungsi pencatatan waktu hadir karyawan tidak boleh dilaksanakan oleh fungsi operasi atau oleh fungsi pembuat daftar gaji dan upah. 


\section{SIMPULAN DAN SARAN}

Simpulan yang dapat peneliti ambil diatas adalah Adanya pemisahan yang jelas antara tugas dan tanggung jawab setiap pihak yang terkait dengan sistem penggajian yang diterapkan oleh PT. Aura Mandiri. Pemisahan tugas dan tanggung jawab bertujuan supaya tidak terjadi tumpang tindih dalam pelaksanaan tugas dan tanggung jawab masing-masing pihak yang terlibat. Pembayaran gaji pada PT. Aura Mandiri menggunakan slip gaji sehingga dapat dengan mudah melakukan pengawasan nama-nama karyawan yang dimasukkan dalam daftar gaji. Dokumen daftar gaji dibuat, diperiksa, disetujui, dan diketahui oleh pihak-pihak yang berkompeten dalam perusahaan. Prosedur penggajian pada PT. Aura Mandiri telah dilaksanakan dengan baik sesuai dengan ketentuan yang berlaku diperusahaan sejak pencatatan jam hadir karyawan sampai disetujuinya daftar gaji dan upah untuk dibayarkan kepada karyawan yang bersangkutan.

Saran peneliti untuk kesempurnaan penelitian kedepannya yaitu adanya pemisahan tugas sesuai bidang agar tidak terjadinya kecurangan. Sudah memanfaatkan teknologi yang lebih canggih seperti sistem fingerprint.

\section{DAFTAR PUSTAKA}

Ambarita. Sistem Informasi Akuntansi Penggajian pada PT. Wesly Tour \& Travel. Medan: STIE IBMI, 2014.

Anthony, Robert. N., Govindarajan, Vijay. 2009. Management Contro. System. Buku 2. Salemba Empat. Jakarta

Cynthiadevi, Renata. 2008. Analisis Efisiensi dan Efektivitas Pengendalian Internal Atas Sistem Penggajian PT Gerbang Tata Gemilang (Bogor). Skripsi. Universitas Indonesia Esa Unggul. Jakarta.

Danke, Yuanita. 2012. Analisis Perancangan Sistem Informasi Akuntansi Pada Siklus Penggajian dalam Rangka Efektifitas Pengendalian Internal. Jurnal Berkala Ilmiah Mahasiswa Akuntansi Vol. 1. Hal. 20-26.

Deigo Jiwandono, Topowijono dan Fransisca Yaningwati. 2017. Analisis Sistem Akuntansi Penggajian dan Pengupahan dalam Rangka Mendukung Pengendalian Intern (Studi pada Pabrik Gula Lestari Patianrowo Kabupaten Nganjuk). Vol. 51 No. 2 Oktober 2017. Jurnal Administrasi Bisnis. Ilmu Administrasi. Universitas Brawijaya Malang.

Dosen Pendidikan (2021). Efektivitas Adalah www.dosenpendidikan.co.id/efektivita s-adalah/ 
Ekonomi, Dosen (2020). Gaji Adalah https://sarjanaekonomi.co.id/gajiadalah/

Fibriyanti, Yenni Vera. (2017). Analisis Sistem Informasi Akuntansi Penggajian Dalam Rangka Efektivitas Pengendalian Internal Perusahaan (Studi Kasus pada PT Populer Sarana Medika, Surabaya). Jurnal Penelitian Ekonomi dan Akuntansi Vol. II No. 1 Februari 2017 https://jurnalekonomi.unisla.ac.id/inde x.php/jpensi/article/view97/96.

Halim, Abdul., Achmad, Tjahjono., Husein,

Muh. Fakhri 2009. Sistem Pengendalian Manajemen. Edisi Revisi. UPP STIM YKPN. Yogyakarta.

Haripratiwi, Ika. 2006. Analisis Sistem Pengendalian Intern Penggajian Karyawan pada BMT AL IKHLAS Yogyakarta STAIN, Surakarta.

Hasan, M. Iqbal, 2002. Metodologi Penelitian dan Aplikasinya. Ghalia Indonesia, Jakarta.

Hasibunan, Malayu S.P. 2008. Manajemen Sumber Daya Manusia. Jakarta: PT Bumi Aksara.

Hidayat, Rahayu, Husaini. 2013. Analisis Penerapan Sistem Akuntansi Penggajian dan Pengupahan dalam Mendukung Pengendalian Intern. Jurnal Administrasi Bisnis Vol. 6. Hal. $1-8$.
Husniyah. Aminatul., Darminto., \& Dwiatmanto. (2015). Analisis Pengendalian Internal Pada Sistem Penggajian Karyawan (Studi pada RSUD Dr. H. Moh. Anwar Sumenep). Jurnal Administrasi Bisnis (JAB) Vol. 28 No. 2 November 2015 https://administrasibisnis.studentjourn al.ub.ac.id.

Laksmi, Riani, Asri. 2013. Manajemen Sumber Daya Manusia. Graha Ilmu, Yogyakarta

Mardalis. 2010. Metode Penelitian. Edisi Pertama. Jakarta: Bumi Aksara.

Moleong, Lexy J, 2006. Metodologi Penelitian Kualitatif. Remaja Rosdakarya Offset, Bandung.

Mulyadi. 2005. Akuntansi Manajemen. STIE YKPN. Yogyakarta

Narbuko, Cholid dan Achmadi, Abu. 2005. Metodologi Penelitian. Bumi Aksara. Jakarta.

Narimawati. U. 2008. Metodologi Penelitian Kualitatif dan Kuantitatif. Bandung: UNIKOM.

Pakadang, Desi. 2013. Efektivitas Sistem Pengendalian Intern Penerimaan Kas Pada Rumah Sakit Gunung Maria Tomohon. Jurnal EMBA. ISSN 23031174. Vol. 1 No. 4 https://ejournal.unsrat.ac.id/index.php/ emba/article/view/2652/2205. 
Pendidikan, Guru. (2020). Sistem

Pengendalian Manajemen Menurut Para Ahli Terlengkap. https://seputarilmu.com/2020/03/siste m-pengendalian-manajemen-menurutpara-ahli.html.

Perpustakaan Universitas Peradaban. Cara Penulisan Daftar Pustaka Harvard Style.

https://perpustakaan.peradaban.ac.id/2 017/05/07/cara-penulisan-daftarpustaka-harvard-style/

Ribka Fininalce Tampi, Janjte J. Tinangon. 2015. Analisis Sistem Pengendalian Intern Terhadap Penggajian pada Grand Sentral Supermarket Tomohon. Vol. 3 No. 3 Sept 2015. Jurnal EMBA Ekonomi dan Bisnis. Universitas Sam Ratulangi Manado

Saraswati, Darminto, Endang. 2014. Analisis Sistem Akuntansi Penggajian dan Pengupahan sebagai Upaya Mendukung Tujuan Pengendalian Intern Perusahaan. Jurnal Adminsitrasi Bisnis Vol. 15. Hal. 1-9.

Sari, Luphi Nikiya. Analsis Efektivitas Sistem Pengendalian Internal Siklus Penggajian Pada UNIPDU Jombang. https://fe.ubhara.ac.id/ojs/index.php/e quity/article/view/204.
Sinain, Sifra G. 2013. Analisis Efektivitas Pengendalian Manajemen Penggajian PT. PLN (PERSERO) Rayon Tomohon. Jurnal EMBA ISSN 23031174. Vol. 1 No. 3. https://ejournal.unsrat.ac.id/index.php. emba/article/view/2529/2065.

Sulung Yogy Hardhanto, David Paul dan Harijanto Sabijono. 2015. Analisis Sistem Pengendalian Intern Penggajian Karyawan pada PT BPR Prisma Dana. Vol. 15 No. 05. Jurnal Berkala Ilmiah Efisiensi. Ekonomi dan Bisnis. Universitas Sam Ratulangi Manado.

Sumarsan, Thomas. 2011. Sistem Pengendalian Manajemen: Konsep, Aplikasi dan Pengukuran Kinerja. Indeks, Jakarta.

Wordpress.com. 2009. Prosedur Akuntansi Penggajian.

https://sanoesi.wordpress.com/tag/sist em-akuntansi-gaji-dan-upah.

Zamzami, Bani. 2013. Analisis Efektivitas Sistem Pengendalian Intern Pada Sistem Penggajian PT Taspen (Persero) Jakarta. Universitas Gunadarma. 
JAFTA - Vol 3 Nomor 2, September (2021) 